\title{
The compression mechanical properties of graphene aerogel
}

\author{
Lulu $\mathrm{Niu}^{1}$, Jing Xie $\mathrm{Xi}^{1,2,3}$, Guangyong $\mathrm{Li}^{4}$, Xuetong Zhang ${ }^{4}$ and Pengwan $\mathrm{Chen}^{1,2,3 \dagger}$ \\ ${ }^{1}$ State Key Laboratory of Explosion Science and Technology, Beijing Institute of Technology, \\ Beijing, China \\ ${ }^{2}$ Explosion Protection and Emergency Disposal Technology Engineering Research Center of the \\ Ministry of Education, Beijing, China \\ ${ }^{3}$ Advanced Technology Research Institute, Beijing Institute of Technology, Jinan, China \\ ${ }^{4}$ Suzhou Institute of Nano-tech and Nano-bionics, Chinese Academy of Sciences, Suzhou, China
}

\begin{abstract}
Graphene aerogel (GA) samples, prepared by the Sol-Gel method, were tested under quasi-static and dynamical compression, and characterized via surface area analyzer and scanning electron microscopy. The results show that the drying method has a significant influence on the sample's microstructure as well as its mechanical compression properties. The supercritical $\mathrm{CO}_{2}$ dried sample has a notable higher specific surface area, and higher compression strength; although the freeze dried sample is much lighter than the supercritical $\mathrm{CO}_{2}$ dried sample, it exhibits a nonlinear superelastic behavior and large compressibility with a reversible strain up to 94\%; under the dynamic compression test, the supercritical $\mathrm{CO}_{2}$ dried sample presents a negative Poisson's ratio behavior whereas the flower-like failure pattern was observed for the freeze dried sample. GA, therefore, is a promising candidate for energy absorption purposes because of its very low density, high specific surface area and porous microstructure.
\end{abstract}

\section{Introduction}

Graphene is a one-atom-thick layer of carbon atoms (approximately $0.4 \mathrm{~nm}$ ) arranged in a hexagonal lattice (1). As a two-dimensional (2D) nanomaterial, it has been the focus of intense interest since its discovery in 2004 due to its remarkable carrier mobility (10000 $\left.\mathrm{cm}^{2} \cdot \mathrm{V}^{-1} \cdot \mathrm{s}^{-1}\right)$, superior thermal conductivity $\left(5000 \mathrm{~W} \cdot \mathrm{m}^{-1} \cdot \mathrm{K}^{-1}\right)(2)$ and excellent mechanical strength (130 GPa) (3). A current challenging problem is about how to overcome the $\pi-\pi$ stacking interactions between graphene sheets and convert the $2 \mathrm{D}$ graphene sheet to a bulk graphene material in order to fully exploit the properties of graphene. Certain methodologies have been devised to prepare three-dimensional (3D) structure graphenes such as aerogels (4), hydrogels (5) and cellular monoliths (6). Among these structures, the aerogel shows a great promise because it can be lighter than air and has thus attracted much attention in recent years (7).

\footnotetext{
* Corresponding author: jxie@ bit.edu.cn

$\dagger$ Corresponding author: pwchen@bit.edu.cn
} 
Aerogels were first synthesized from silica gels by replacing the liquid component with gas (8). Nowadays, the aerogels are prepared from molecular precursors (generally graphene oxides) by sol-gel methods and followed by either freeze or supercritical drying to replace the solvents with air (9). NASA used silica aerogel to capture particles from comet Wild 2 in 2004 (10). Laboratory hypervelocity impact experiments conducted by Japanese scientists have verified that at impact velocities below $6 \mathrm{~km} / \mathrm{s}$ the projectiles of aluminum oxide, olivine, or soda lime glass with diameters ranging from 10 to $400 \mu \mathrm{m}$ were captured without fragmentation by the silica aerogel collector of $0.03 \mathrm{~g} \cdot \mathrm{cm}^{-3}(11)$. In the present work, therefore, the graphene aerogel (GA) was test mechanically (quasi-static and dynamical) for exploring its potential application in the field of energy absorption as a lightweight material.

\section{Experiments}

\subsection{Preparation of graphene aerogels}

GA samples were prepared by the Sol-Gel method following the procedure shown in Fig.1. The graphene oxide (GO) solution as a precursor, which has a lateral size of $20 \mathrm{~nm}$ on average, was mixed with ascorbic acid (VC). The mixed solution in a homogeneous dispersion was cast into sample molds to form the graphene hydrogels through a hot water bath process. Subsequently, the graphene hydrogels were immersed in an ethanol solution via a solvent exchange, and then supercritical $\mathrm{CO}_{2}$ drying and freeze drying was applied to obtain GAs, respectively.

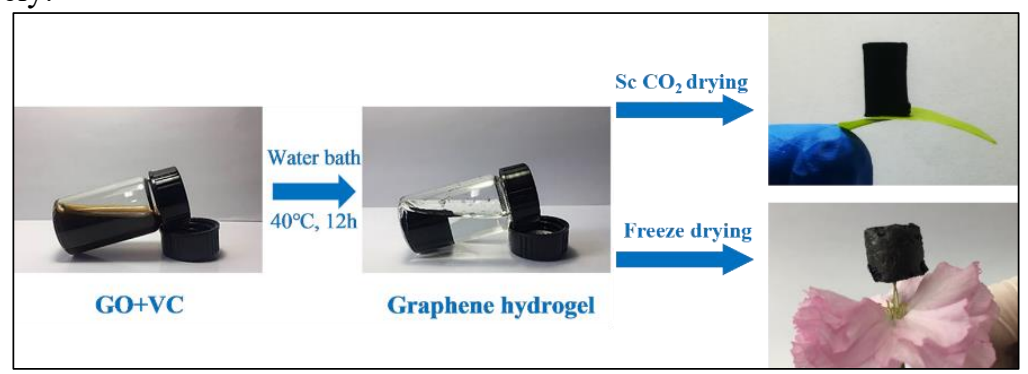

Fig. 1. The preparation of graphene aerogels. (Sc is in short of supercritical)

\subsection{Mechanical tests}

Quasi-static compression testing was performed on a universal material testing machine (Instron 3365) at room temperature with a constant compression speed of $3 \mathrm{~mm} \cdot \mathrm{min}^{-1}$. Dynamic compression tests were conducted on a split Hopkinson pressure bar (SHPB, Fig.2), which was used to measure the stress-time relationship of graphene aerogel during deformation. The bars of the SHPB facility was made of hard aluminum alloy with Young's modulus of $70 \mathrm{GPa}$, density of $2.7 \mathrm{~g} / \mathrm{cm}^{3}$ and wave speed of $5100 \mathrm{~m} / \mathrm{s}$. The diameter of the striker bar, incident bar and transmission bar is $14 \mathrm{~mm}$, and their length are 400, 1200 and $1200 \mathrm{~mm}$, respectively. 


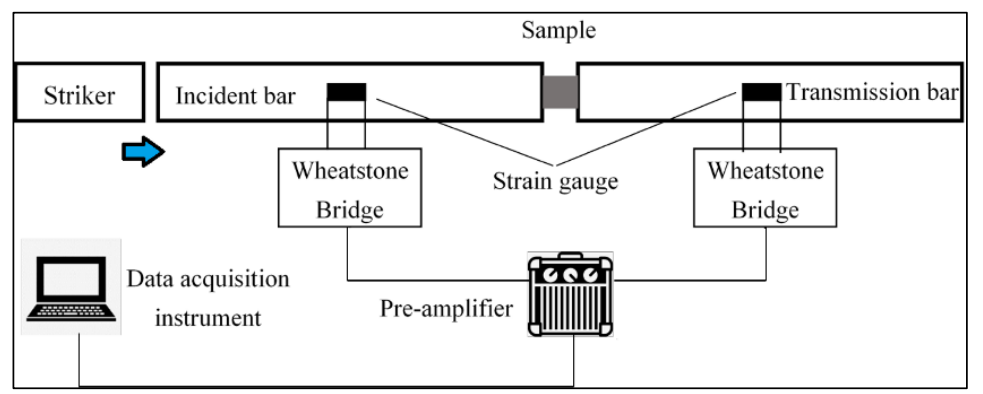

Fig. 2. The schematic diagram of the split Hopkinson pressure bar facility.

\subsection{Characterizations}

The apparent density $\left(\rho_{\mathrm{a}}\right)$ of GA samples was calculated from the mass (electronic scale, BSM-120.4) and volume of cylindrical samples, and the true density $\left(\rho_{\mathrm{t}}\right)$ was measured using the gas pycnometer (Micromeritics, AccuPyc II 1340). The relative density $\left(\rho_{\mathrm{r}}\right)$ is defined as the ratio of the apparent density to the true density, thus the porosity $\mathrm{P}$ of GA samples was calculated by ignoring the air inside the aerogels: $\mathrm{P}(\%)=\left(1-\rho_{\mathrm{a}} / \rho_{\mathrm{t}}\right) \times 100 \%=\left(1-\rho_{\mathrm{r}}\right) \times 100 \%$.

The pore structure of samples was investigated by a surface area analyzer (Micrometrics, ASAP 2460), the specific surface area was calculated utilizing the Brunauer-Emmett-Teller (BET) method. The microstructure of the samples was observed by scanning electron microscope (SEM, Quanta 400 FEG).

\section{Results \& Discussion}

The properties of the tested GA samples are summarized in Table. 1. The isotherms (Fig. 3) of GA samples have a typical type IV hysteresis loop, meaning the GA samples contain mesopores. The specific surface area of GA prepared by supercritical $\mathrm{CO}_{2}$ drying is 530.87 $\mathrm{m}^{2} \cdot \mathrm{g}^{-1}$, which is higher than the $\mathrm{MoS}_{2}$ aerogel $\left(18 \mathrm{~m}^{2} \cdot \mathrm{g}^{-1}\right)(12)$, graphene-CNT aerogels $(315$ $\left.\mathrm{m}^{2} \cdot \mathrm{g}^{-1}\right)(13)$, silica aerogels $\left(450 \mathrm{~m}^{2} \cdot \mathrm{g}^{-1}\right)(14)$ and the 3D polypyrrole-graphene foam (463 $\left.\mathrm{m}^{2} \cdot \mathrm{g}^{-1}\right)(15)$. Whereas freeze drying is not beneficial for achieving a higher specific surface area.

Table 1. The properties of GA samples.

\begin{tabular}{|c|c|c|c|c|c|c|}
\hline $\begin{array}{l}\text { Drying } \\
\text { method }\end{array}$ & $\begin{array}{l}\text { Apparent } \\
\text { density } \\
\left(\mathrm{mg} \cdot \mathrm{cm}^{-3}\right) \\
\end{array}$ & $\begin{array}{l}\text { True } \\
\text { density } \\
\left(\mathbf{m g} \cdot \mathrm{cm}^{-3}\right) \\
\end{array}$ & $\begin{array}{l}\text { Relative } \\
\text { density } \\
(\%)\end{array}$ & $\begin{array}{l}\text { Porosity } \\
(\%)\end{array}$ & $\begin{array}{l}\text { Specific } \\
\text { surface area } \\
\left(\mathrm{m}^{2} \cdot \mathrm{g}^{-1}\right)\end{array}$ & $\begin{array}{l}\text { Pore } \\
\text { volume } \\
\left(\mathrm{cm}^{3} \cdot \mathrm{g}^{-1}\right)\end{array}$ \\
\hline $\begin{array}{l}\mathrm{Sc} . \mathrm{CO}_{2} \\
\text { drying }\end{array}$ & 35.25 & \multirow{2}{*}{3337.87} & 1.06 & 98.94 & 530.87 & 2.46 \\
\hline $\begin{array}{l}\text { Freeze } \\
\text { drying }\end{array}$ & 1.5 & & 0.05 & 99.95 & 15.63 & 0.04 \\
\hline
\end{tabular}

Fig. 3 shows the results of the quasi-static uniaxial compression test of GA. Compared with the freeze drying, the GA samples prepared by the supercritical $\mathrm{CO}_{2}$ drying have a higher compression strength. According to the slope of the stress-strain curve (Fig.3(a)), the stressstrain curve is divided into three stages, which are (i) elastic stage, (ii) plastic stage, and (iii) densification stage. The calculated elastic modulus $\mathrm{E}$ of the GA sample is $2.9 \mathrm{MPa}$, thus the specific stiffness $(\mathrm{E} / \rho)$ is $82.27 \mathrm{kN} \cdot \mathrm{m} \cdot \mathrm{kg}^{-1}$, which is higher than that of common silica aerogel $\left(3.89 \mathrm{kN} \cdot \mathrm{m} \cdot \mathrm{kg}^{-1}\right)(16)$. The GA samples prepared by the freeze drying, however, present a 
nonlinear superelastic behavior and large compressibility with a reversible strain up to $94 \%$ and corresponding stress over $0.16 \mathrm{MPa}$. After 30 cycles of loading-unloading, the peak stress decayed by $30 \%$ roughly, implying a promising direction that tuning the ice-crystal growth in the process of freeze drying to obtain a desirable superelasticity of GA samples.
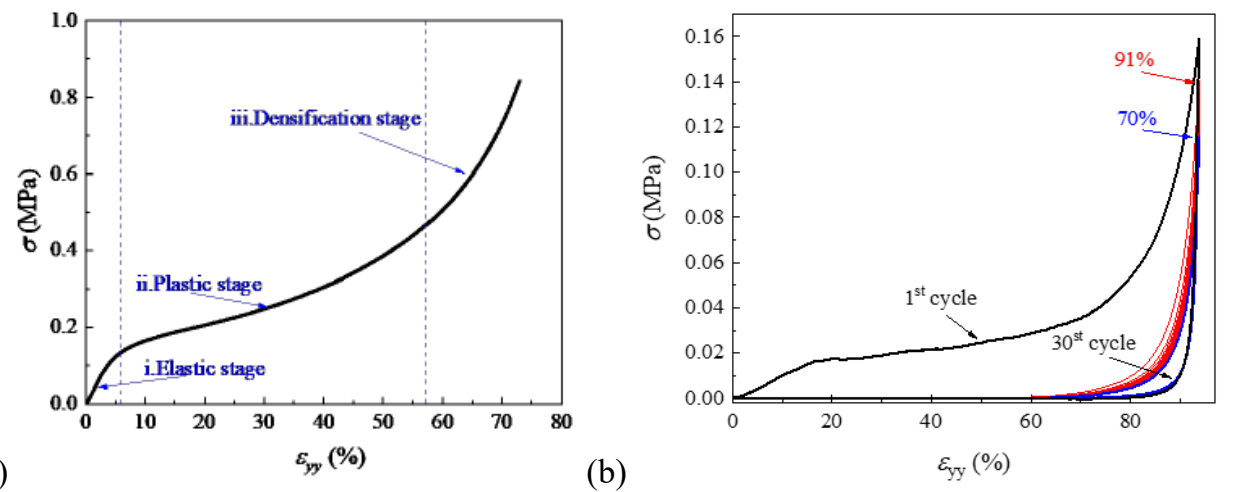

Fig. 3. Quasi-static compression properties of the graphene aerogel. (a): Supercritical $\mathrm{CO}_{2}$ drying; (b): Freeze drying.

The wave impedance of the GA samples prepared by supercritical $\mathrm{CO}_{2}$ drying and freeze drying is $187.08 \mathrm{~kg} \cdot \mathrm{m}^{-2} \mathrm{~s}^{-1}$ and $12.85 \mathrm{~kg} \cdot \mathrm{m}^{-2} \mathrm{~s}^{-1}$, respectively, which is significantly lower than that of the Al alloy bar $\left(4.35 \times 10^{5} \mathrm{~kg} \cdot \mathrm{m}^{-2} \mathrm{~s}^{-1}\right)$. Thus, the typical stress-strain curves are not applicable here. Instead, the stress-time curves are shown in Fig.4 to qualitatively illustrate the wave attenuation generated by the GA samples. The incident wave is almost completely reflected for the first 5 times, and the transmitted wave is weak and barely seen. Until the $6^{\text {th }}$ time, the signal of the transmitted wave is suddenly amplified, but the transmitted wave shape is different between the supercritical $\mathrm{CO}_{2}$ drying sample and the freeze drying sample. The transmitted wave of the supercritical $\mathrm{CO}_{2}$ drying sample gradually decays, whereas only part of the stress wave propagates to the transmitted bar for the freeze drying sample at the $6^{\text {th }}$ time and becomes enhanced at the $7^{\text {th }}$ time.
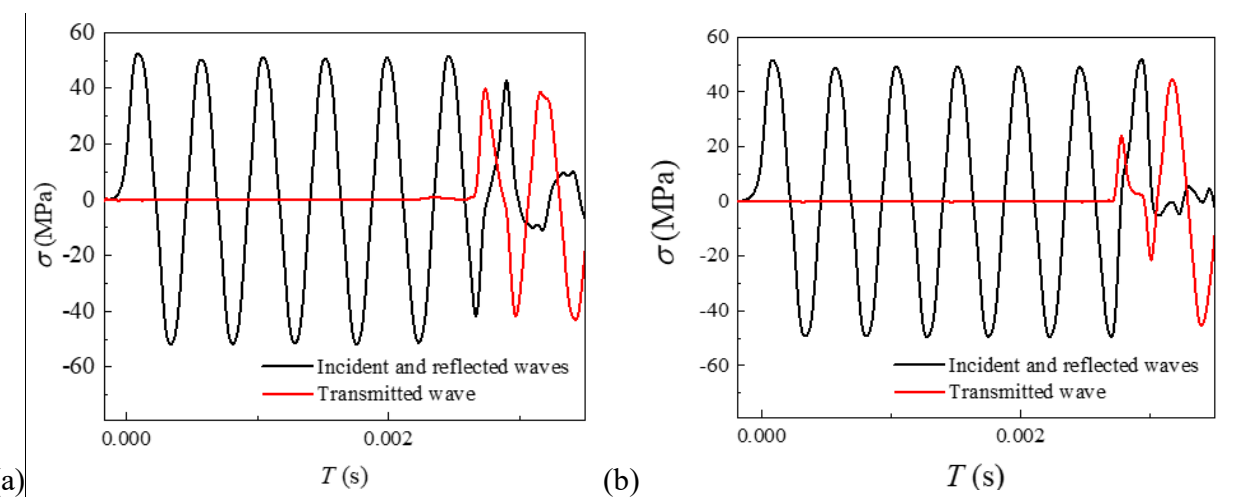

Fig. 4. Quasi-static compression properties of the graphene aerogel. (a): Supercritical $\mathrm{CO}_{2}$ drying; (b): Freeze drying.

The above-described difference of the mechanical behaviors can be explained by the microstructural characterization (Fig. 5). Before compression, supercritical $\mathrm{CO}_{2}$ dried GA samples present a nanoporous 3D network containing partial overlapping graphene sheets with a large number of randomly distributed pores. After quasi-static and dynamical compression, the graphene sheets are densified and have an obvious layered fold structure and a negative Poisson's ratio deformation pattern. The freeze 
dried GA sample, however, is another story. Due to the orientations and squeezing mechanisms of ice crystals during the freezing process, the as-fabricated graphene aerogel exhibit unidirectional aligned or chaotic networks, thus the freeze dried samples do not produce the negative Poisson's ratios during the quasi-static and dynamic compression. The "buckling" induced elastic-instability randomly happens out-of-plane, resulting in transverse expansion and flower-like failure pattern.

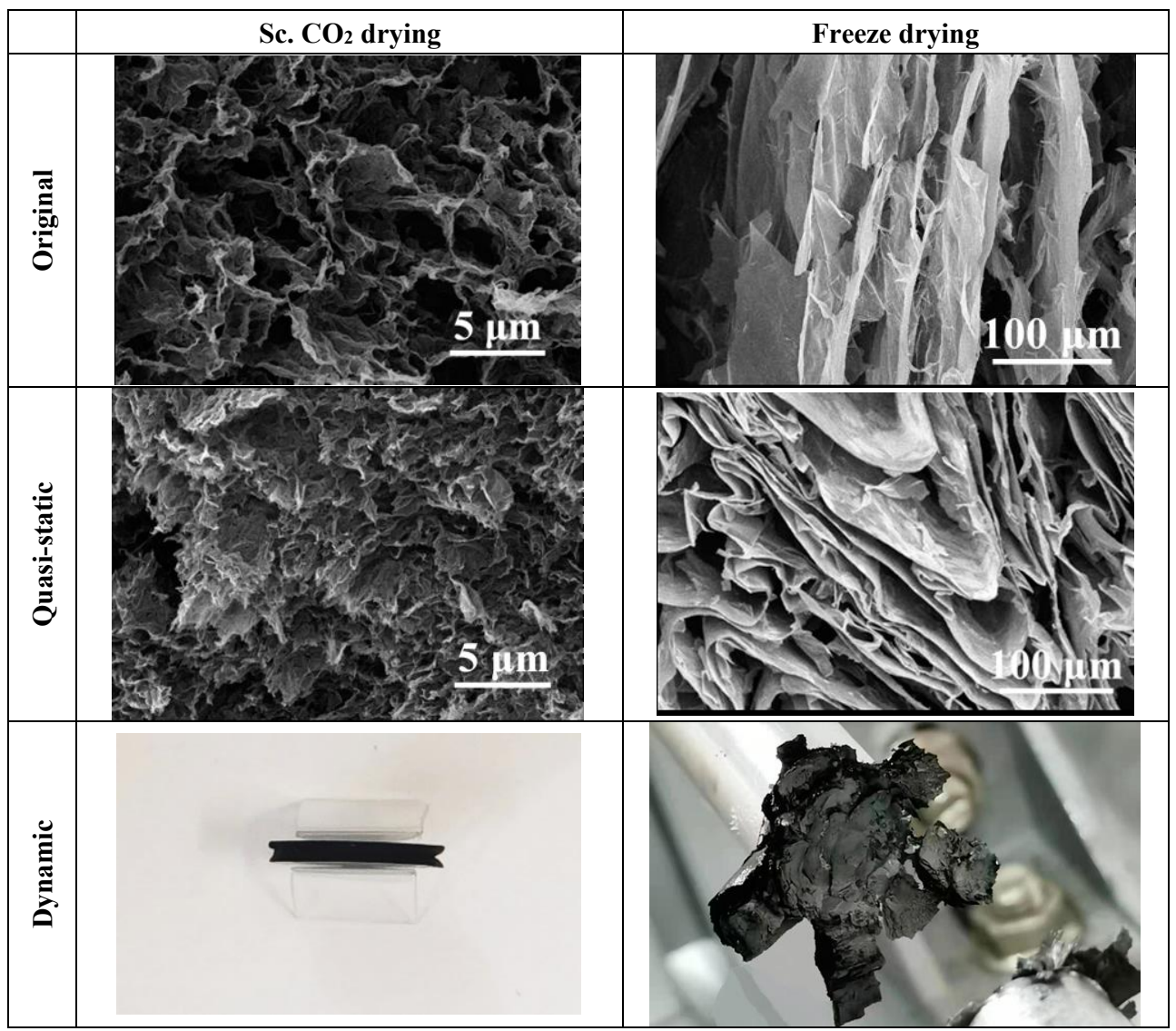

Fig. 5. The original microstructural and deformation behaviors of GA samples.

\section{Conclusions}

The GA samples were prepared by the sol-gel method and then dried either via supercritical $\mathrm{CO}_{2}$ or freeze drying. The drying method has a significant influence on the sample's microstructure and mechanical compression properties. The main conclusions are summarized as follows:

- The supercritical $\mathrm{CO}_{2}$ dried sample has a notable higher specific surface area of $530.87 \mathrm{~m}^{2} \cdot \mathrm{g}^{-1}$, while the freeze dried sample is much lighter $\left(1.5 \mathrm{mg} \cdot \mathrm{cm}^{-3}\right)$ than the supercritical $\mathrm{CO}_{2}$ dried sample.

- The quasi-static compression strength of supercritical $\mathrm{CO}_{2}$ dried samples is higher than that of freeze dried samples, but the freeze dried samples exhibit a nonlinear superelastic behavior and large compressibility with a reversible strain up to $94 \%$ and corresponding stress over $0.16 \mathrm{MPa}$.

- Due to the difference of microstructure between supercritical $\mathrm{CO}_{2}$ dried sample and freeze dried sample, the dynamic deformation pattern is entirely contrary: 
supercritical $\mathrm{CO}_{2}$ drying produces the negative Poisson's ratio behavior whereas the flower-like failure pattern was observed for the freeze dried sample.

The project is supported by the Research Fund Program for Young Scholars of Beijing institute of technology. We also acknowledge support from the Youth Scholars project of the state key laboratory of explosive science and technology (Grants \# QNKT19-07). Special thanks are given to Prof. D. Rittel for his kind help in discussing the manuscript.

\section{References}

1. K. S. Novoselov, et al., Electric Field Effect in Atomically Thin Carbon Films. Science (80-. ). 306, 666-669 (2004).

2. D. Saini, Synthesis and functionalization of graphene and application in electrochemical biosensing. Nanotechnol. Rev. (2016).

3. C. Lee, X. Wei, J. W. Kysar, J. Hone, Measurement of the Elastic Properties and Intrinsic Strength of Monolayer Graphene. Science (80-. ). 321, 385-388 (2008).

4. H. Hu, Z. Zhao, W. Wan, Y. Gogotsi, J. Qiu, Ultralight and Highly Compressible Graphene Aerogels. Adv. Mater. 25, 2219-2223 (2013).

5. Y. Xu, K. Sheng, C. Li, G. Shi, Self-Assembled Graphene Hydrogel via a One-Step Hydrothermal Process. ACS Nano 4, 4324-4330 (2010).

6. L. Qiu, J. Z. Liu, S. L. Y. Chang, Y. Wu, D. Li, Biomimetic superelastic graphenebased cellular monoliths. Nat. Commun. (2012) https:/doi.org/10.1038/ncomms2251.

7. G. Gorgolis, C. Galiotis, Graphene aerogels: a review. 2D Mater. 4, 032001 (2017).

8. S. S. KISTLER, Coherent Expanded Aerogels and Jellies. Nature 127, 741-741 (1931).

9. X. Zhang, et al., Mechanically strong and highly conductive graphene aerogel and its use as electrodes for electrochemical power sources. J. Mater. Chem. 21, 6494 (2011).

10. S. M. Jones, Aerogel: Space exploration applications. J Sol-Gel Sci Techn 40, 351357 (2006).

11. Y. Kitazawa, et al., Hypervelocity impact experiments on aerogel dust collector. $J$. Geophys. Res. E Planets 104, 22035-22052 (1999).

12. M. A. Worsley, et al., Mechanically robust 3D graphene macroassembly with high surface area. Chem. Commun. (2012) https:/doi.org/10.1039/c2cc33979j.

13. S. Kabiri, D. N. H. Tran, T. Altalhi, D. Losic, Outstanding adsorption performance of graphene-carbon nanotube aerogels for continuous oil removal. Carbon N. Y. 80, 523-533 (2014).

14. T. Woignier, J. Phalippou, Mechanical strength of silica aerogels. J. Non. Cryst. Solids 100, 404-408 (1988).

15. Y. Zhao, et al., Highly Compression-Tolerant Supercapacitor Based on Polypyrrole-mediated Graphene Foam Electrodes. Adv. Mater. 25, 591-595 (2013).

16. A. H. Alaoui, T. Woignier, G. W. Scherer, J. Phalippou, Comparison between flexural and uniaxial compression tests to measure the elastic modulus of silica aerogel. J. Non. Cryst. Solids 354, 4556-4561 (2008). 